\title{
Modelling the effect of forest cover on shallow landslides at the river basin scale
}

\author{
James C. Bathurst ${ }^{\mathrm{a}, *}$, C. Isabella Bovolo ${ }^{\mathrm{a}}$, Felipe Cisneros $^{\mathrm{b}}$ \\ a School of Civil Engineering and Geosciences, Newcastle University, Newcastle upon Tyne NE1 7RU, UK \\ b Universidad de Cuenca, Cuenca, Programa para el Manejo de Agua y Suelo (PROMAS), Department of Water and Soil Resources Engineering, \\ Avenida 12 de abril S/N, Cuenca, Ecuador
}

\section{A R T I C L E I N F O}

\section{Article history:}

Received 8 October 2008

Received in revised form 5 May 2009

Accepted 6 May 2009

Available online $\mathrm{xxx}$

\section{Keywords:}

Ecuador

Landslides

Modelling

Model uncertainty

Reforestation

River basin

Root-binding

SHETRAN

\begin{abstract}
A B S T R A C T
The potential for reducing the occurrence of shallow landslides through targeted reforestation of critical parts of a river basin is explored through mathematical modelling. Through the systematic investigation of land management options, modelling allows the optimum strategies to be selected ahead of any real intervention in the basin. Physically based models, for which the parameters can be evaluated using physical reasoning, offer particular advantages for predicting the effects of possible future changes in land use and climate. Typically a physically based landslide model consists of a coupled hydrological model (for soil moisture) and a geotechnical slope stability model, along with an impact model, such as basin sediment yield. An application of the SHETRAN model to the $65.8-\mathrm{km}^{2}$ Guabalcón basin in central Ecuador demonstrates a technique for identifying the areas of a basin most susceptible to shallow landsliding and for quantifying the effects of different vegetation covers on landslide incidence. Thus, for the modelled scenario, increasing root cohesion from 300 to 1500 Pa causes a two-thirds reduction in the number of landslides. Useful information can be obtained even on the basis of imperfect data availability but model output should be interpreted carefully in the light of parameter uncertainty.
\end{abstract}

(c) 2009 Elsevier B.V. All rights reserved.

\section{Introduction}

It has long been known that a well developed forest cover minimizes the occurrence of shallow landslides on steep hillslopes (e.g. Rice et al., 1969; Sidle et al., 1985; Pearce et al., 1987). Nevertheless, anthropogenic pressure has caused extensive elimination of natural forests from hillslopes worldwide while clear felling associated with forestry operations regularly removes all tree cover from large areas of hillslope. The result is an increase in the incidence of shallow landslides and debris flows, in soil erosion and in the injection of sediment into river systems (e.g. Amaranthus et al., 1985; Sidle et al., 1985; Guthrie, 2002; Dhakal and Sidle, 2003; Keim and Skaugset, 2003; Sidle and Ochiai, 2006). The subsequent impacts, including loss of soil fertility, blocked transport corridors, river and reservoir sedimentation, deterioration of aquatic habitat and threat to human life, can have major social, economic and environmental repercussions (e.g. Larson and Albertin, 1984; Tejwani, 1984; Kessel, 1985; Dhital, 2003; López et al., 2003; Sidle and Ochiai, 2006). There is a strong interest, therefore, in ways of minimizing the increased landslide occurrence. In particular, just as forest

\footnotetext{
* Corresponding author. Tel.: +44 191246 4878; fax: +441912464961.

E-mail address: j.c.bathurst@ncl.ac.uk (J.C. Bathurst).
}

removal is seen as a cause of the problem, so the re-introduction or maintenance of forest cover is a possible solution (e.g. Lu et al., 2001; Vanacker et al., 2007).

A natural spatial scale at which to consider landsliding, its impacts and its control is the river basin. In some cases it is possible to control erosion by reforesting an entire basin (e.g. Douguédroit, 1981; Lukey et al., 2000). However, it is unrealistic to expect this at a large scale in areas where people rely on the land for their livelihoods. On the other hand, landslides do not normally occur uniformly across a basin; typically they are concentrated in critical areas of topography, soil and land use. It has therefore been proposed that reforestation of only small parts of a basin, carefully targeted, could produce a disproportionately large reduction in landslide occurrence and sediment yield (e.g. Reid and Page, 2002).

Testing this hypothesis by field trials would take many years. Mathematical modelling, though, offers the possibility of a systematic investigation of different land management strategies, allowing the most effective locations, size of area and even plantation density for reforestation to be identified rapidly. This paper therefore examines basin scale landslide modelling and its use in assessing the impact of forest cover on slope stability. There is rather limited literature on the topic and the paper responds to the need to provide potential practitioners with background information and 
example applications. Its aim is to review current capability and to provide an introduction for those who have a limited familiarity with the topic, rather than to develop the topic further. It therefore begins with basic statements on the significance of the river basin scale, the role of modelling and the processes by which vegetation cover affects landslide occurrence. It then addresses in more detail the modelling requirements, especially the type of model needed to represent land use change impacts, and describes the features of one particular model (SHETRAN), including its limitations and its setting in the context of other models in the literature. The use of the model to quantify the effect of targeted reforestation on landslide occurrence is illustrated for a focus site in Ecuador. Some final comments are provided on future research directions.

\section{The river basin}

The river basin or drainage area is the natural hydrological unit, for which it is possible to determine balances between the major constituent fluxes of rainfall, evaporation and river discharge, along with groundwater storage. All the processes and events that occur in a basin influence the fluxes of water, sediment and contaminants at the basin outlet and those fluxes are therefore an integration of all upstream processes and events. Shallow landslides are hydrologically driven and the basin is therefore an appropriate spatial scale at which to study not only their onsite impacts on the hillslope but also their offsite impacts such as channel and reservoir sedimentation. Studies in New Zealand, for example, show landslides contributing significantly to the basin scale sediment yield (Hicks et al., 2000; Reid and Page, 2002). The larger basin (of area greater than $100 \mathrm{~km}^{2}$ ) is also an appropriate scale at which to account for landslide impacts in regional scale hazard mapping (Guzzetti et al., 1999) and in landscape modelling (Claessens et al., 2007). More generally, the basin scale is convenient for quantifying the hydrological, sediment yield and hazard effects of land use and climate change.

\section{Basin scale modelling}

A mathematical model is a simplified representation of a river basin and hydrological processes, used for simulating and predicting hydrological events and their consequences (e.g. Clarke, 1973). On the one hand, a model is a means of testing our understanding of the processes, and the integration of processes, responsible for the hydrological behaviour of a basin. If a model produces results comparable with the observation, then our understanding is at least consistent with reality for the observed conditions and the model is presumed to be valid for those conditions. If there is a discrepancy between model output and observation, our understanding is deficient and requires further development.

On the other hand, models can be used for a range of practical purposes. Of relevance to this paper is the capability to carry out systematic investigations of different land management strategies for minimizing landslide incidence and impact, enabling the optimum strategy to be determined in advance of any real intervention in the basin. Similarly, models can be used to identify the critical locations for landslide occurrence, the spatial extent of such areas and the degree to which tree plantation could reduce landslide occurrence.

\section{Effect of tree cover on shallow landsliding}

The effect of tree cover on hillslope stability is well documented (e.g. Sidle et al., 1985; Greenway, 1987; Sidle and Ochiai, 2006). On the mechanical side, trees stabilize the soil layer through the binding action of their roots, which provide considerable apparent cohesion. Tree weight (surcharge) acts to destabilize the slope but its effect is usually relatively minor compared with that of soil weight and root-binding. On the hydrological side, the relatively high interception evaporation and transpiration of trees reduces soil moisture content and thus the pore water pressure which is critical for landslide occurrence. A greater amount of rainfall is then needed to trigger landslides. Against this effect, the relatively high porosity of forest soils may allow fast saturation of the deeper soil layers. Tree cover also influences snow accumulation and melt rates and thus the spatial distribution and movement of water in the soil.

Change to the vegetation cover is one of the principal means by which human activity affects slope stability. Increases in landslide incidence following logging or deforestation have been widely reported (e.g. Amaranthus et al., 1985; Sidle et al., 1985; Guthrie, 2002).

\section{The modelling challenge}

In view of the foregoing, the challenge to the modeller is to simulate shallow landslides and debris flows, along with their sediment yield, as a function of:

- spatially and temporally varied rainfall and snowmelt (as the triggers);

- land use (to provide the root-binding and evaporation effects of vegetation);

- spatial variation in topography, vegetation properties and soil properties (to be relevant at the basin scale).

Some of the difficulties and the state of the art are reviewed by Collison and Griffiths (2004) and Sidle and Ochiai (2006).

A range of modelling approaches is available, including:

- empirical models, calibrated from measurements, e.g. threshold curves which indicate whether or not landslides may occur;

- statistical methods, such as discriminant analysis, which identify statistically those basin properties which correlate positively or negatively with landslide occurrence;

- physically based slope stability analysis, which accounts for the main determining mechanisms using the fundamental equations of physics.

This paper is concerned with the physically based approach.

\section{Physically based models}

Physically based models are based on the fundamental equations of physics, such as the equations of mass, momentum and energy conservation, and theoretically and experimentally derived relationships (such as the infinite-slope, factor-of-safety equation for slope stability). Unlike empirical models, their parameters have a physical meaning (such as soil cohesion and vegetation aerodynamic resistance). These parameters can therefore be changed using physical reasoning and experimental data to represent an altered state of the catchment. For example, a catchment could be modelled with its current forest cover (with typical parameter values such as a low aerodynamic resistance of $5 \mathrm{~s} \mathrm{~m}^{-1}$ ); the vegetation parameters could then be changed to represent grass cover (which has, for example, a typically higher resistance of perhaps $50 \mathrm{~s} \mathrm{~m}^{-1}$ ) and the simulation repeated to investigate the effect of the land use change.

To illustrate the point further, a comparison is presented of empirical and physically based models. An empirical threshold 


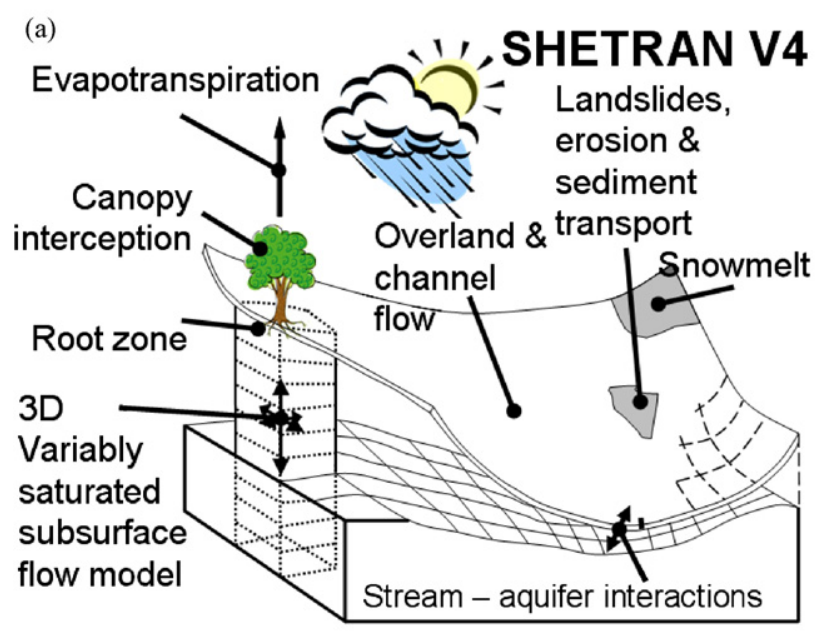

(a)

(c)

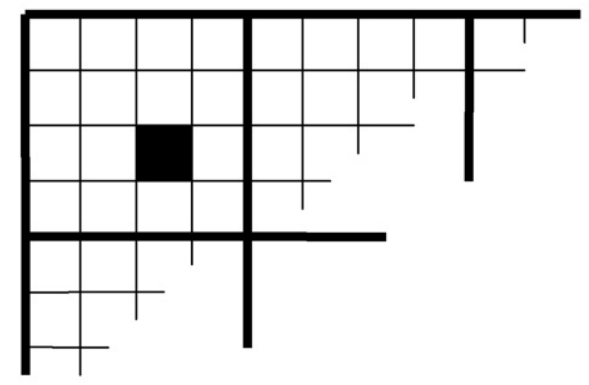

(d) (b)

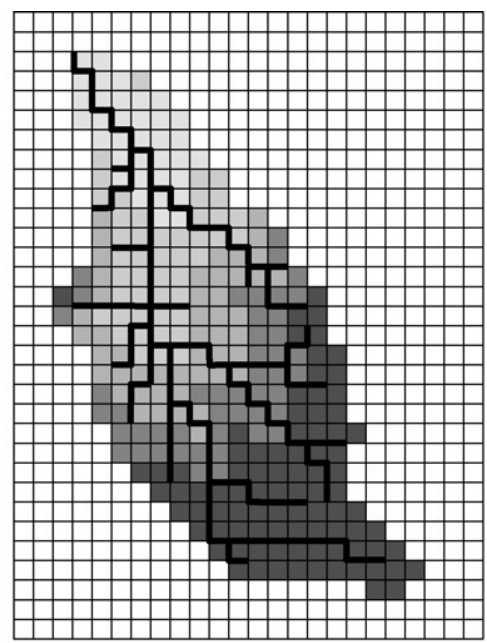

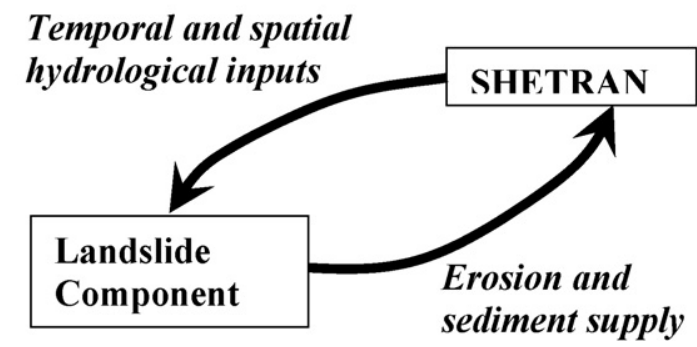

Fig. 1. (a) Schematic diagram of the SHETRAN model; (b) an example of a SHETRAN model grid showing spatial variability in elevation and the river channel network in bold lines; (c) the relationship between the SHETRAN grid (in bold) and the landslide subgrid network (fine lines); (d) the relationship between the SHETRAN hydrology and sediment transport model and the landslide erosion and sediment yield component.

model is created from measurements taken over a period of time of the rainfall characteristics for which landslides do and do not occur. A curve is then calibrated as

$I=a D^{-b}$

where $I=$ mean storm rainfall intensity and $D=$ storm duration, such that combinations of intensity and duration lying above the curve would be expected to trigger landslides while combinations below would not (e.g. Caine, 1980). The equation might apply well to current conditions in a given region. However, the coefficient $a$ and exponent $b$ have no physical meaning; they are simply derived in the calibration process. Therefore, there is no objective way in which to alter them so as to represent a change in climate, land use or region.

By contrast the physically based model of soil shear strength (the Mohr-Coulomb equation) contains parameters with a physical meaning:

$s=c^{\prime}+c_{r}+(\sigma-u) \tan \phi^{\prime}$

where $s=$ soil shear strength, $c^{\prime}=$ effective soil cohesion, $c_{r}=$ root cohesion, $\sigma=$ normal stress, $u=$ pore water pressure and $\varphi^{\prime}=$ effective angle of internal friction. The parameters can be measured at a site or even quantified approximately using data from the literature. For example, measurements show that root cohesion varies from a few hundred Pascals for grass to around $20 \mathrm{kPa}$ for some tree types (e.g. Preston and Crozier, 1999; Sidle and Ochiai, 2006, pp. 103-104). Objective changes in parameter values can therefore be made, giving physically based models particular advantages in predicting the impacts of possible future changes in catchment conditions.
As physically based models tend to be run as continuous simulation models over periods of years (rather than as single event models), they also have an advantage in being able to generate the appropriate antecedent soil moisture conditions for a landsliding event.

Physically based, spatially distributed landslide models typically have the following composition:

- a coupled hydrological model (providing the soil moisture conditions) and geotechnical stability model (typically the one-dimensional infinite-slope model) to simulate landslide occurrence on a spatially distributed basis and as a function of time-varying soil moisture conditions;

- an impact model, such as debris flow patterns or landslide sediment yield, to provide offsite impacts in addition to the onsite impacts represented by the landslide occurrence map produced by the above simulation;

- a basis in digital elevation model and geographical information system technologies.

\section{The SHETRAN model}

SHETRAN is a physically based, spatially distributed, basin hydrology, sediment transport and contaminant transport modelling system (Ewen et al., 2000) (Fig. 1a). Of relevance to this paper, SHETRAN provides the hydrological and sediment transport framework for simulating rain- and snowmelt-triggered landsliding and sediment yield. In particular it simulates: 
- the land phase of the hydrological cycle, accounting in a fully integrated way for vegetation interception and transpiration, snowmelt, overland flow, variably saturated subsurface flow and river/aquifer interaction;

- sediment yield as a function of soil erosion by raindrop impact and overland flow and transport by overland and channel flow;

- shallow landsliding and the resulting sediment yield.

Full details of the hydrology and sediment transport components are given in Bathurst et al. (1995), Wicks and Bathurst (1996) and Ewen et al. (2000) and are therefore not repeated here. Details of the equations and data needs of the SHETRAN landslide model are also available elsewhere (Burton and Bathurst, 1998) and therefore only the following summary is presented, drawn from Bathurst et al. (2005, 2006, 2007). The occurrence of shallow landslides is determined as a function of the time- and space-varying soil saturation conditions simulated by the hydrology model, using the one-dimensional infinite-slope, factor-of-safety equation. This includes allowance for the effect of vegetation root cohesion. However, in line with observation and theory (e.g. Sidle et al., 1985) shallow landslides are not simulated for slopes of less than $25^{\circ}$. For each landslide the volume of eroded material is determined from the soil depth and the area of the landslide. Using a rule-based approach derived from observation, the eroded material is routed down the hillslope as a debris flow if the vegetation is forest or if the landslide occurs in a gully. However, if the landslide occurs on a planar grass-covered slope, there is no onward transport. The model has an option to allow the debris flow to collect additional sediment by scouring along its track. Deposition by the debris flow occurs once the gradient falls below a certain critical value (the default value being $10^{\circ}$ ) and takes place over the run-out distance, which is calculated as a percentage of the difference in elevation between the landslide location and the location of the critical gradient (the default value being $40 \%$ ). The proportion of the material reaching the channel network is then calculated and fed to the SHETRAN sediment transport model for routing to the basin outlet (Fig. 1d).

Within SHETRAN, the spatial distribution of catchment properties, rainfall input and hydrological response is achieved in the horizontal direction through the representation of the catchment and its channel system by an orthogonal grid network (Fig. 1b) and in the vertical direction by a column of horizontal layers at each grid square. However, grid resolution is typically large (as much as 1 or $2 \mathrm{~km}$ ) compared with the length dimensions of shallow landslides (typically around $10-100 \mathrm{~m}$ ). The central feature of the landslide model, therefore, is the use of derived relationships (based on a topographic index) to link the SHETRAN grid resolution at which the basin hydrology and sediment yield are modelled, to a subgrid resolution at which landslide occurrence and erosion is modelled (Fig. 1c). That is, using the topographic index, the SHETRAN grid saturated zone thickness is distributed spatially at the subgrid resolution. If the factor-of-safety analysis indicates slope failure at a subgrid element, that element counts as one landslide. Through this dual resolution design, the model is able to represent landsliding at a physically realistic scale while remaining applicable at basin scales (up to $500 \mathrm{~km}^{2}$ ) likely to be of interest, for example feeding a reservoir. The subgrid discretization, landslide susceptibility and potential landslide impact (e.g. sediment delivered to the stream system) are determined in advance using a geographical information system and this information is stored in a "look-up" table. During the time-varying simulation SHETRAN provides information on the temporal variation in soil moisture content as input to the landslide model (Fig. 1d). As landslides occur, their predetermined sediment impacts are passed to the SHETRAN sediment transport component from the look-up table and the sediment is routed along the channel system to the basin outlet.
Applications of the landslide model are described in Bathurst et al. $(2005,2006,2007)$. Some recent examples of applications of the SHETRAN hydrological and sediment transport model are presented in Lukey et al. (2000), Bathurst et al. (2002, 2004), Adams et al. (2005) and Adams and Elliott (2006).

\section{SHETRAN data needs}

The data required by SHETRAN are:

(i) precipitation and potential evaporation input data to drive the simulation, preferably at hourly intervals;

(ii) topographic, soil, vegetation, sediment and geotechnical properties to characterize the catchment on a spatially distributed basis;

(iii) discharge records, sediment yield and a landslide inventory, for testing the model output.

It is usually possible to obtain information on the catchment property data through field measurements and laboratory analysis and from national agencies. For example, the soil properties required for the infinite-slope analysis can be obtained from laboratory analysis of field samples while digital elevation data are provided by national agencies (or even the worldwide web). However, it is rare outside small research basins to be able to obtain all the required time-varying data. Rainfall data are often at the daily, rather than hourly, scale and a basin with a landslide inventory map may not also have, for example, sediment yield data. Various techniques such as rainfall disaggregation and regional scaling of water and sediment discharges then need to be employed to fill the gaps (e.g. Bathurst et al., 2005, 2006, 2007).

\section{Simulation uncertainty}

All river basin models are approximations of reality and their simulation results are therefore subject to uncertainty. The sources of the uncertainty include model design and evaluation of the model parameters (parameterization). It is emphasized that this uncertainty does not prevent models from being applied usefully but an understanding of the causes and effects of the uncertainty is essential for a realistic interpretation of the simulation output.

\subsection{Model accuracy}

Several features of SHETRAN's design limit the accuracy with which it can represent landslides. First, the one-dimensional infinite-slope analysis ignores all upslope, downslope and lateral boundaries and is therefore subject to uncertainty where groundwater flow or topography produce forces that are significant in directions other than slope-normal (e.g. Iverson and Reid, 1992; Collison and Griffiths, 2004). Second, the model subgrid resolution (usually determined by the resolution of the available digital elevation model) limits both the ability of the model to account for topographic controls on landsliding, such as hillslope hollows and gullies, and the representation of local slope angle. Further, lack of data may limit the ability to represent the local spatial variability in soil properties and other conditions which allows a landslide to occur in one place while an apparently similar neighbouring site remains stable (e.g. Montgomery et al., 1997; Burton et al., 1998) The SHETRAN landslide model is therefore likely to be most relevant to basins where slopes are laterally homogeneous and gradient dominates topography as the landslide control. 


\subsection{Parameter uncertainty}

It is generally acknowledged that the parameterization of physically based, spatially distributed models involves uncertainty (e.g. Beven and Binley, 1992; Beven, 2001, pp. 19-23; Guimarães et al., 2003) and that this uncertainty must be accounted for in the model output. Sources of the uncertainty include:- the mismatch between the scales at which property measurements are made (e.g. saturated conductivity is measured at the scale of an auger hole) and the model grid scale at which the parameter value is applied (a resolution of typically tens to hundreds of metres); the current inability to measure all the model parameters at every model subgrid element (resulting in the use of estimated or assumed values) and, associated with the use of estimated values, potentially unrealistic combinations of parameter values which may, in reality, show some correlation, such as soil depth and topography. Several techniques have been developed to quantify the effects of parameter uncertainty on output uncertainty, usually as some form of uncertainty envelope (e.g. Beven and Binley, 1992; Ewen and Parkin, 1996; Guzzetti et al., 2006). Greater availability of data can also constrain the uncertainty (e.g. Ebel and Loague, 2006).

\subsection{Elimination of unrealistic landslides}

The current impracticality of measuring the required landslide model parameters at every SHETRAN subgrid element across the entire basin means that the parameter values must be estimated in most cases, e.g. based on data obtained at a coarser resolution or at a few sampling points. A certain proportion of elements is then characterized with unrealistic combinations of parameter values (e.g. a deep soil on a steep slope) and is simulated to be unconditionally unstable, even in dry conditions. Before carrying out the time-varying simulation, it is therefore necessary to eliminate these instabilities so that only sites with physically realistic combinations of parameter values are retained. One approach is to remove from the analysis all landslides which occur at the very start of the simulation (e.g. the first $24 \mathrm{~h}$ ) before any rain is applied (Bathurst et al., 2005, 2007).

\section{Comparison of models}

SHETRAN is one of three basin scale landslide models that have maintained an appearance in the literature over the last decade, the other two being SHALSTAB and dSLAM/IDSSM. All three combine a digital representation of topography with an infinite-slope stability model and some form of hydrological model. Comparison of the three indicates a range of designs aimed at different applications.

\subsection{SHALSTAB (shallow stability model)}

This model is described in a number of publications (e.g. Montgomery and Dietrich, 1994; Dietrich et al., 2001). It is the simplest process-based model that can account for topographic control on the pore water pressure development responsible for shallow slope instability. The dominant control is assumed to be local surface topography causing shallow subsurface flow convergence, except at the steeper slopes where gradient becomes more important. It is a steady state system (so does not represent timevarying conditions). It assumes zero cohesion (so cannot represent the binding effects of roots). Hydrology is represented solely by groundwater flow, which is modelled spatially using a stream tube system based on topography. Simulated landslides occur typically at topographically determined flow convergences and can create confined debris flows along river channels. The model is aimed at the spatial distribution of the relative potential for landsliding across the landscape. In support of forestry operations it can be used to identify sites of high, medium and low hazard and thus the areas where forestry can be practised most safely. Its original region of application was the western USA, typically in basins of hectares to a few square kilometres but potentially also to much larger areas.

\section{2. dSLAM/IDSSM (distributed shallow landslide model/integrated dynamic slope stability model)}

This model is described in Wu and Sidle (1995), Dhakal and Sidle (2003) and Sidle and Ochiai (2006) amongst others. Like SHALSTAB it generates landslides at sites of topographic flow convergence, with hydrology represented principally by groundwater flow modelled spatially using a stream tube system based on topography. It can create confined debris flows. However, it is a continuous simulation model (so can allow for time-varying inputs) and contains a dynamic root cohesion model (so allows for time variation in root properties as a function of tree growth and logging). It does not incorporate evaporation, so is most applicable to wet autumn and winter conditions in temperate maritime regions. It has particular strengths in assessing the spatial and temporal effects of timber harvesting on slope stability. Its original region of application was the Pacific northwest of North America, typically in basins of hectares to a few square kilometres.

\subsection{SHETRAN}

This is a continuous simulation model incorporating the full land phase of the hydrological cycle plus soil erosion and sediment transport. Whereas the other two models were designed explicitly as landslide models with the hydrology limited to what was considered to be the dominant process, SHETRAN is a hydrology model to which a landslide component has been added. Root cohesion is accounted for but is generally time invariant. In principle the model can represent zones of topographic convergence but it is probably more typically applicable to planar hillslope landslides and unconfined debris flows. Also, whereas the other two models operate solely at the resolution of the digital elevation model, offering the potential to model the exact spatial location of individual observed landslides but over only a limited basin scale, the dual resolution basis of SHETRAN limits the ability to model such a oneto-one agreement but enables the model to be applied at scales of at least $500 \mathrm{~km}^{2}$. The model's strengths are in determining basin scale patterns of landslide occurrence and sediment yield and assessing land use and climate change impacts. Its current published areas of application are the Alps and Pyrenees in Europe but it is potentially applicable to all geographical regions.

Currently there is no industry-standard approach to basin scale landslide modelling and the topic continues to attract innovative research efforts. Recent developments include Borga et al. (2002), Chen and Lee (2003), Vanacker et al. (2003), Iida (2004), Gorsevski et al. (2006) and others covered by Meisina and Scarabelli (2007), Sidle and Ochiai (2006) and a special issue of Hydrological Processes (Crosta and Frattini, 2008).

\section{Example application: the Guabalcón basin, Ecuador}

An application of the SHETRAN model to the Guabalcón basin, Ecuador, is presented to show how a model can be used to investigate the effectiveness of targeted reforestation in reducing landslides and to illustrate the capabilities and difficulties of physically based modelling. The available data set was incomplete and it is stressed that the application is therefore illustrative of a 


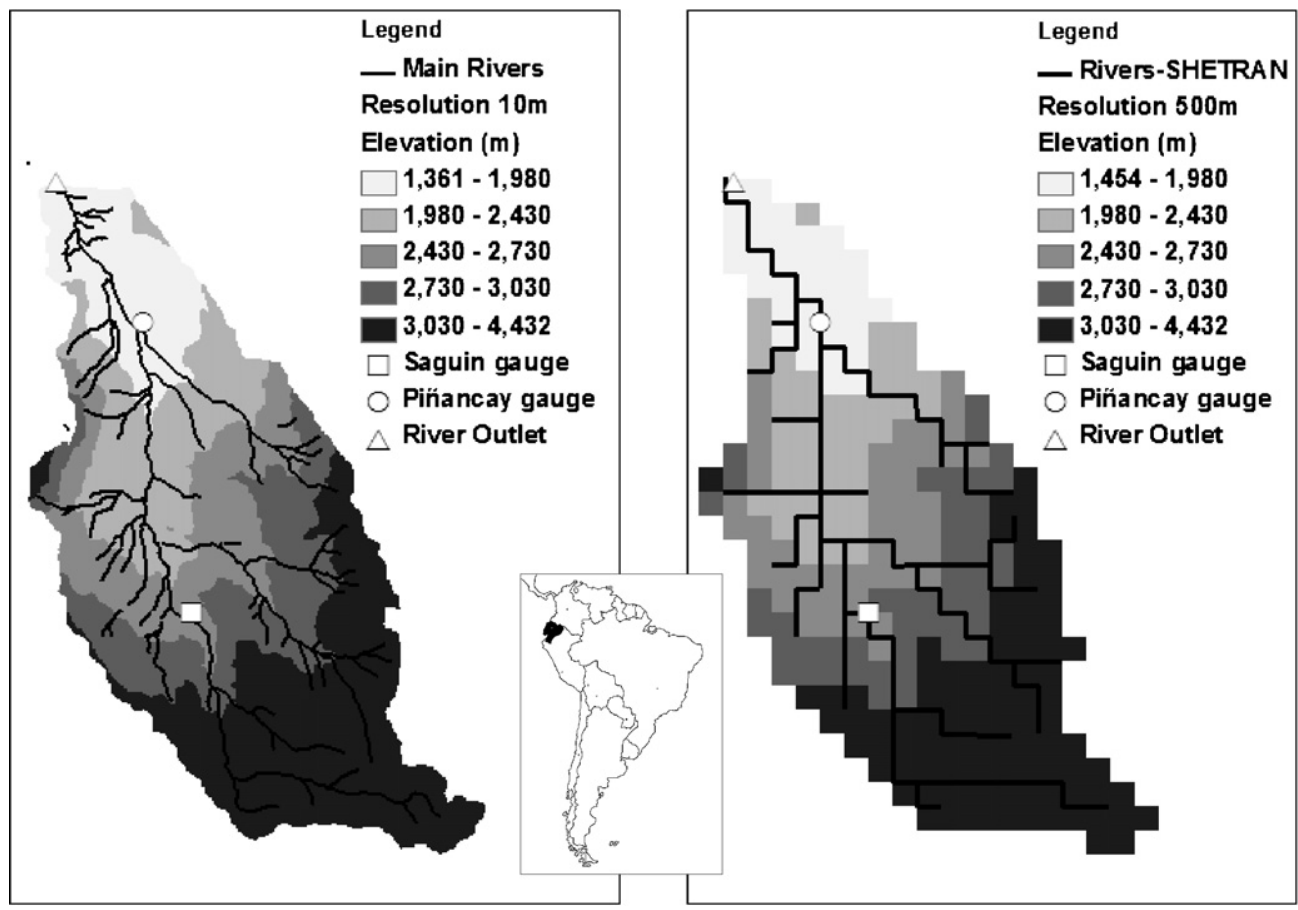

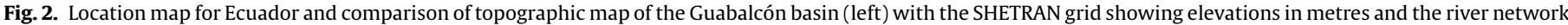
(right).

technique rather than an accurate portrayal of the test site. Nevertheless, it also shows how an imperfectly parameterized model can still be used to carry out an initial exploration of a problem.

\subsection{The Guabalcón basin}

The Río Guabalcón has a basin area of $65.8 \mathrm{~km}^{2}$ and is part of the Río Chanchán basin in the central Andean region of Ecuador. The Chanchán itself is part of the Guayas system which drains to the Pacific Ocean. The region is subject to shallow landslides and debris flows as well as spectacular deep-seated landslides.

Basin elevation ranges from 1370 to $4420 \mathrm{~m}$ (Fig. 2) and threequarters of the basin has slopes of more than $25 \%$. The geology consists of roughly two-thirds tertiary period rocks (principally mid to late Eocene to Miocene but with a small amount of Cretaceous formation at the head of the basin) and one-third quaternary material. A range of soils has developed, varying with altitude. The head of the basin is characterized by andosols, which have a high organic content and remarkable water-holding properties, enabling them to release water at an almost constant rate through the dry season (e.g. Buytaert et al., 2005; Harden, 2006). The middle and lower parts of the basin are characterized by cambisols and leptosols (the latter being shallow soils less than $0.25 \mathrm{~m}$ deep overlying rock). Land use and vegetation change from the higher to lower elevations in the sequence páramo (characteristic grassland on the andosols), pasture, cultivated land and pasture, and mattoral. Mean annual rainfall varies considerably with altitude and location, from under $700 \mathrm{~mm}$ at the lower elevations to over $1000 \mathrm{~mm}$ at higher elevations. Total amounts may be rather higher in El Niño years. Most of the rain falls between January and May.

\subsection{Data availability}

Using a 10-m resolution digital elevation model (DEM), the SHETRAN grid was discretized with a 500-m resolution (Fig. 2) and the landslide model subgrid resolution was set at $10 \mathrm{~m}$. Soil prop- erty data were obtained from laboratory analysis of soil samples collected in the Guabalcón and neighbouring river basins. These data include the soil hydraulic property curves needed for the SHETRAN hydrological model (i.e. the soil moisture/matric potential curve and the soil moisture/hydraulic conductivity relationship, Van Genuchten, 1980). However, it was found necessary to adjust the saturated conductivity values in the calibration process. Apart from the leptosols, the soils have two layers, of which the upper was given a thickness of $0.25 \mathrm{~m}$ based on measurements. The total depth was adjusted in the calibration process and given a value of $4 \mathrm{~m}$. Vegetation property data were based on a SHETRAN library of values developed from past model applications (e.g. Lukey et al., 2000). For the landslide model, root cohesion was based on literature data such as Sidle et al. (1985), Preston and Crozier (1999), Abernethy and Rutherfurd (2001) and Sidle and Ochiai (2006). Vegetation surcharge was assumed to be negligible.

Hourly rainfall records were obtained from six gauges, mostly at or just beyond the western edge of the basin. These were processed to provide model input in five altitudinal bands (corresponding to the individual gauge elevations) plus a small sixth domain on the western edge of the basin. Daily potential evapotranspiration was calculated for a reference condition using the Penman-Monteith equation, from automatic weather station data available for 2005-2007 at the Namza (1850m elevation), Chontamarca $(2254 \mathrm{~m})$ and Marianza $(3450 \mathrm{~m})$ stations, enabling an altitudinal dependency to be determined. A baseline time series of model actual evapotranspiration was calculated for the calibration period (2007-2008) using the Penman-Monteith equation with data for the Namza station (using a Food and Agriculture Organization calculator at http://www.fao.org/docrep/X0490E/x0490e00.HTM and assuming a grass cover); this series was then corrected for altitude using the dependency and distributed spatially according to the bands used for rainfall input.

Discharge gauging stations were established in 2007 at Saguin (basin area $13.3 \mathrm{~km}^{2}$ ) and Piñancay $\left(57.35 \mathrm{~km}^{2}\right)$ but not at the outlet $\left(65.8 \mathrm{~km}^{2}\right)$. Daily mean discharges and some point values were 

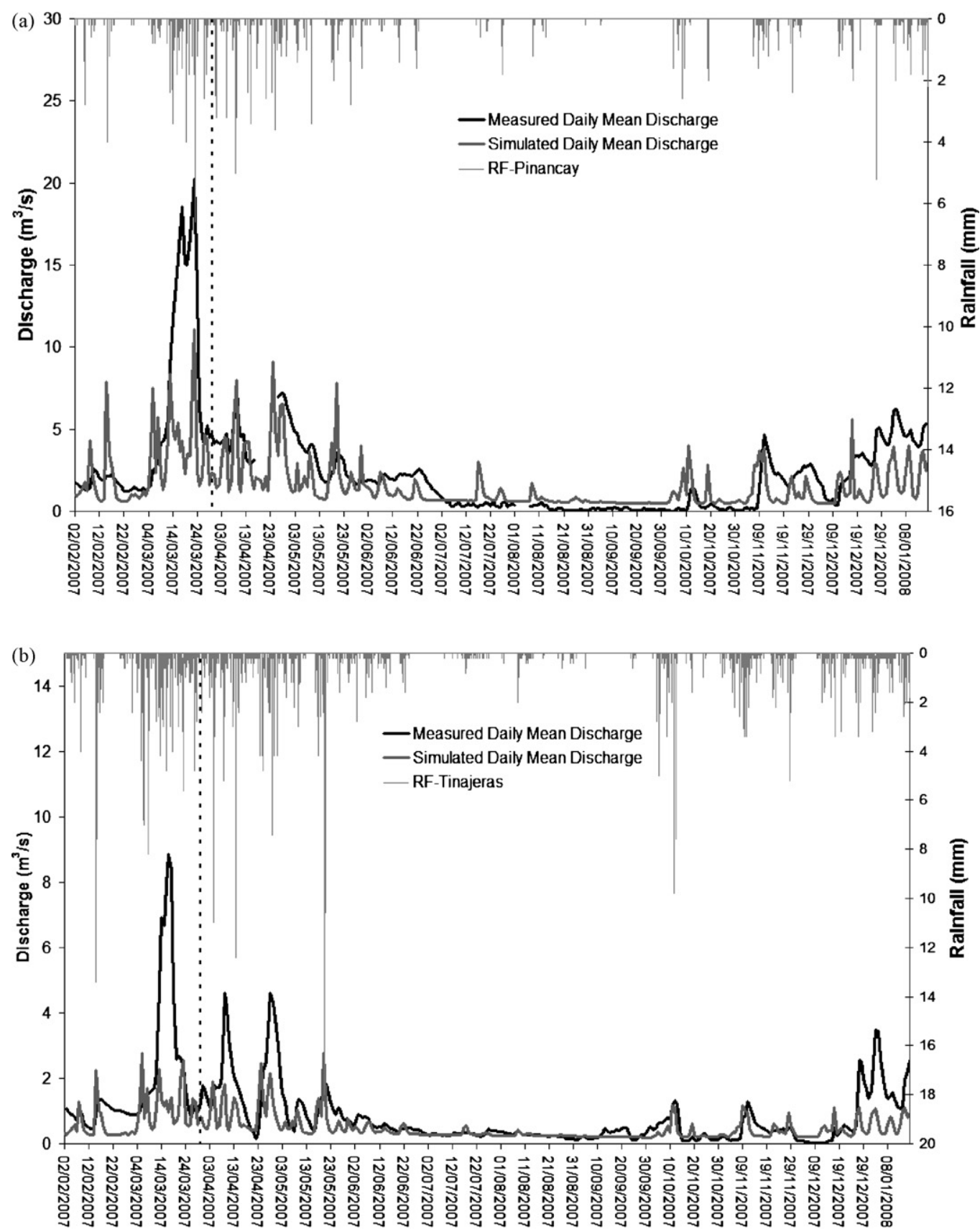

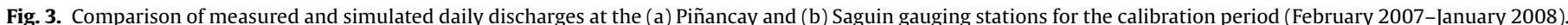

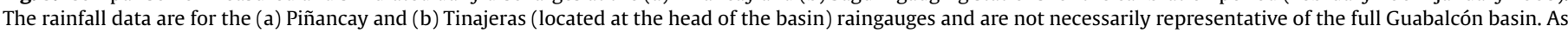
described in the text, rainfall data were not available for the Tinajeras raingauge in the period before the dotted line.

available. Above Saguin, the basin has a good cover of páramo grassland and shrubs and soil erosion is relatively limited. In the middle basin, above Piñancay, there is general cultivation, steep slopes, shallow landsliding and rather higher erosion.

\subsection{Calibration}

The overall simulation period was June 2005-January 2008, for which rainfall and evaporation data were available. Calibration, however, was limited to February 2007-January 2008, for which period discharge data were available. The principal calibration parameters were the overland flow resistance coefficient (which was varied as a function of vegetation) and the soil depth and saturated conductivity. Even so, as required by the physical basis of the SHETRAN model, the parameter values were mostly constrained to lie within physically realistic ranges. The calibration procedure itself was limited to adjusting the parameters to optimize the fit between the measured and simulated daily discharge series over the calibration period.

The calibration process was hampered by a number of factors:

- the highly localized variations in rainfall are not well sampled by the existing raingauge network. The altitudinally banded rainfall input is therefore only an approximation of reality;

- the spatial heterogeneity in rainfall rendered inaccurate the use of regression equations to fill gaps in raingauge records. For exam- 
Table 1

Values of the principal SHETRAN soil parameters for the simulations.

\begin{tabular}{|c|c|c|c|c|c|c|}
\hline Soil type & Soil layer & $\begin{array}{l}\text { Depth } \\
(\mathrm{m})\end{array}$ & $\begin{array}{l}\text { Bulk dry density } \\
\left(\mathrm{kg} \mathrm{m}^{-3}\right)\end{array}$ & $\begin{array}{l}\text { Saturated conductivity } \\
\left(\mathrm{m} \mathrm{day}^{-1}\right)\end{array}$ & $\begin{array}{l}\text { Van Genuchten exponent } \alpha \text { for } \\
\text { soil moisture content/tension } \\
\text { curve }\left(\mathrm{cm}^{-1}\right)\end{array}$ & $\begin{array}{l}\text { Van Genuchten exponent } n \text { for } \\
\text { soil moisture content/tension } \\
\text { curve }(-)\end{array}$ \\
\hline \multirow[t]{2}{*}{ Andosol } & Upper & 0.3 & 550 & 2 & 0.00221 & 1.377 \\
\hline & Lower & 0.7 & 660 & 2 & 0.00102 & 1.138 \\
\hline \multirow[t]{2}{*}{ Cambisol (eutric) } & Upper & 0.25 & 1000 & 0.3 & 0.00061 & 1.421 \\
\hline & Lower & 4.0 & 1000 & 2 & 0.0004 & 1.601 \\
\hline \multirow[t]{2}{*}{ Cambisol (vertic \& dystric) } & Upper & 0.25 & 1400 & 0.3 & 0.278 & 1.377 \\
\hline & Lower & 4.0 & 1500 & 2 & 0.278 & 1.601 \\
\hline Leptosol & & 0.25 & 1390 & 0.1 & 0.0504 & 1.061 \\
\hline
\end{tabular}

ple, data were not available for the highest gauge, at Tinajeras, for February and March 2007. The gap was filled using a regionally derived rainfall-altitude relationship but the resulting data proved unsatisfactory for modelling some of the observed discharge record;

- the stage-discharge relationships derived for the river gauging stations and used for converting the stage (i.e. water surface elevation) measurements into discharge values may not be entirely accurate, especially for the higher flows:

- the evapotranspiration was calculated for a grass cover, which may not be representative of all parts of the basin;

- the calibration period, of just 1 year, is relatively short and may therefore represent only a limited range of conditions;

- there is some uncertainty associated with the soil parameter values as they are extrapolated to the grid squares on the basis of spatially limited samples.

As a consequence it was possible to achieve only an approximate calibration and the comparison of the measured and simulated time series was carried out visually. Fig. 3 compares the simulated and measured daily discharges at the two gauging stations. There is good order of magnitude agreement and the main events are captured by the simulation. However, there are also clear discrepancies: for example, the inability to model the major hydrograph in March 2007 (because of the gap in the Tinajeras rainfall record) is obvious. Also, the simulated discharges are more variable in time and more responsive to rainfall than the measured discharges. Potentially this suggests a difficulty in representing the distinctive water-discharging properties of the soil. It was found necessary to apply relatively high saturated conductivity values to simulate the constant flow through the dry season. However, this arrangement may conflict with the requirement to simulate a slow subsurface transfer of rainwater to the river system in the wet season apparently indicated by the measured discharge response. On the other hand, the discrepancy is greater for the Piñancay than for the Saguin simulation; this is the opposite of what might be expected given that it is the andosols in particular which have the remarkable properties and these soils occur mainly in the Saguin headwaters. It is not clear, therefore, to what extent the discrepancy reflects deficiencies in the simulations or in the data. Therefore, given its approximate nature, the calibration is felt to provide a sufficient technical basis for landslide modelling in the basin but the results should be viewed as illustrative rather than an accurate representation of reality.

Values of the key model soil parameters are shown in Table 1. The relatively high saturated conductivity values for the lower layers of the cambisols and andosols $\left(2 \mathrm{mday}^{-1}\right)$ were found to be necessary to simulate the characteristic water-discharging properties of the basin soil through the dry season. For the andosols this conductivity was also applied to the upper layer. As data were not available on the geotechnical soil properties needed for the infinite- slope stability model, soil cohesion was set at $4.67 \mathrm{kPa}$, soil angle of internal friction was set at $29.8^{\circ}$ and soil depth to the shear surface was set at $0.85 \mathrm{~m}$ based on data collected in the Spanish Pyrenees by Bathurst et al. (2007). The Strickler overland flow resistance coefficient (in $\mathrm{m}^{1 / 3} \mathrm{~s}^{-1}$ ) (the reciprocal of the Manning coefficient) was set at 2 for bushes and shrubs, 3 for crops, 4 for natural grass and 2 for native forest, i.e. a higher resistance for forest and shrubs than for crops and grass.

It can be seen that there is a difference between the SHETRAN grid soil depth and the landslide model subgrid soil depth (the depth to the shear surface). This arises from calibration requirements and approximations in the model parameterization. When such cases occur, the model design ensures that soil moisture is conserved between the two scales. However, the use of a single depth to shear surface for the whole basin, where the soil depth is variable, is likely to be a source of uncertainty for the landslide simulations. Across a basin, soil depth can vary significantly. Typically this is as a function of geomorphology, so that deeper soils occur in hollows and areas of topographic convergence, while shallower soils occur in more exposed areas such as ridges. Even within a small section of hillslope there can be a significant variation in depth: Burton et al. (1998), for example, measured variations from $0.1 \mathrm{~m}$ to over $1.2 \mathrm{~m}$ within a square of $250 \mathrm{~m} \times 250 \mathrm{~m}$. Slope stability calculations are sensitive to soil depth, with a consequent impact on model simulations (e.g. Wu and Sidle, 1997). Minimizing the errors requires detailed depth measurements across the catchment, which is currently unrealistic except over small areas.

\subsection{Landslide simulations}

An important first step in the SHETRAN model application is determining the spatial distribution of the critical saturated soil depth required for a landslide to occur. (The saturated depth is calculated as a relative value, defined as the thickness of the saturated zone divided by soil depth, above the shear surface.) If during the subsequent simulation the time-varying saturated depth exceeds the critical value at any point, then according to the model there is a landslide. The spatial distribution of the critical saturated soil depth thus effectively provides a map of the distribution of failure probability; zones with a high critical depth have a high probability of failure. A high probability of failure is also expected to correlate with high slope angle. Fig. 4 therefore compares the SHETRAN map of critical saturated soil depth with the map of slope angle derived from the basin digital elevation model. The comparison confirms that zones of high slope angle have high probabilities of failure.

Superimposed on the maps in Fig. 4 are the landslide sites obtained through the simulation. Mostly these are concentrated in a zone of high critical saturated depth and slope angle and of particular soil parameter values on the western side of the basin and this zone is shown in greater detail in Fig. 5. The area in white shows the extent of landsliding for a relatively weak vegetation root cohesion 


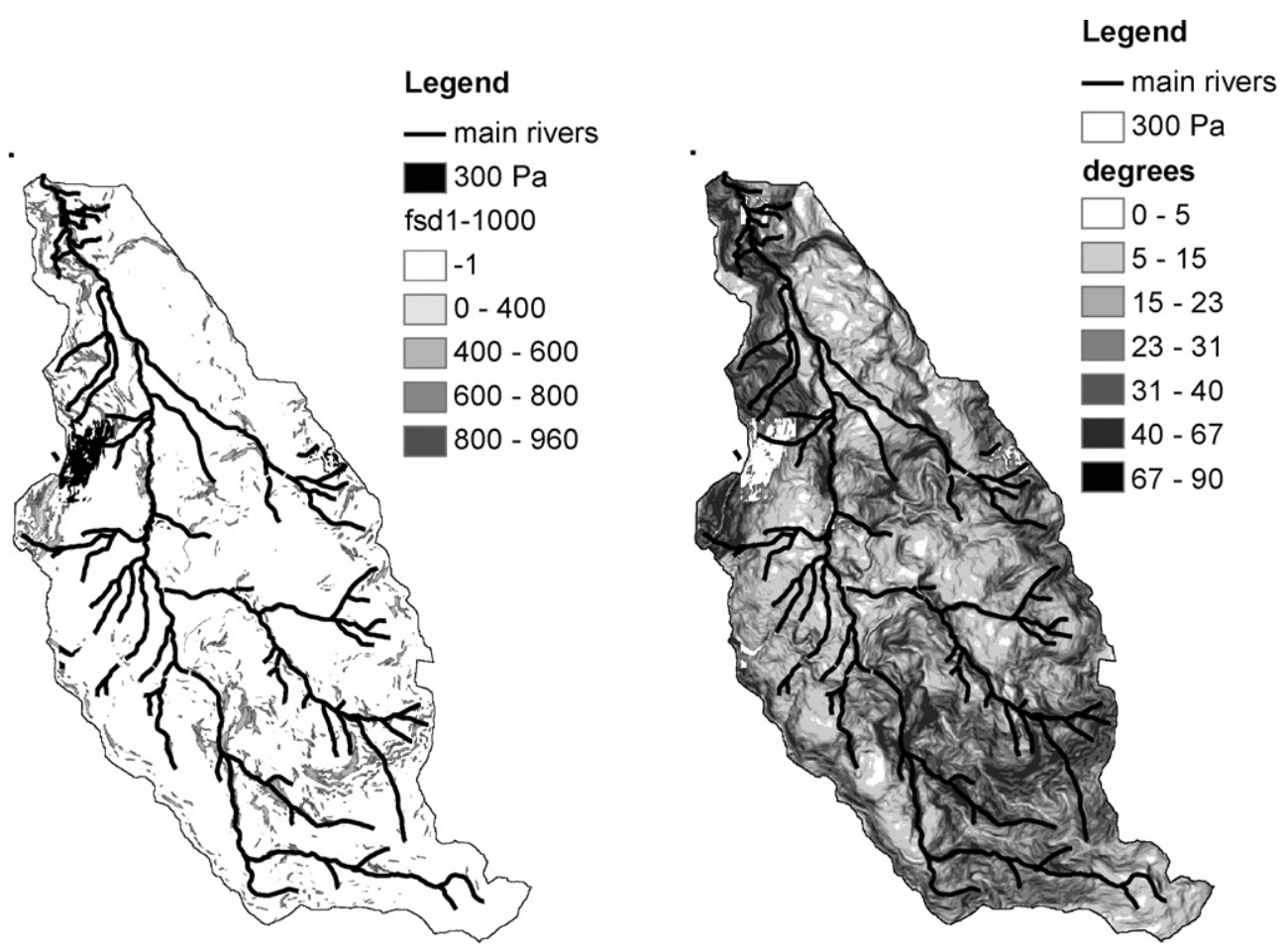

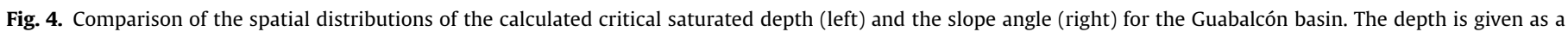
relative value between 0 and 1 , multiplied by 1000 . Simulated landslides are shown in black (left) and white (right) for a root cohesion of 300 Pa.

of $300 \mathrm{~Pa}$, characteristic of pasture. The area in black (which lies on top of the white) shows how the extent is reduced as the cohesion is increased to $1500 \mathrm{~Pa}$, at the low end of the range of additional cohesion which can be provided by forest cover. In other words the figure demonstrates the potential for reducing landslides in a grassland terrain by planting trees. In this case, some but not all of the landsliding would be eliminated.

Fig. 5 shows all the landslides obtained from the simulation and thus illustrates broad regions of potential instability. As noted

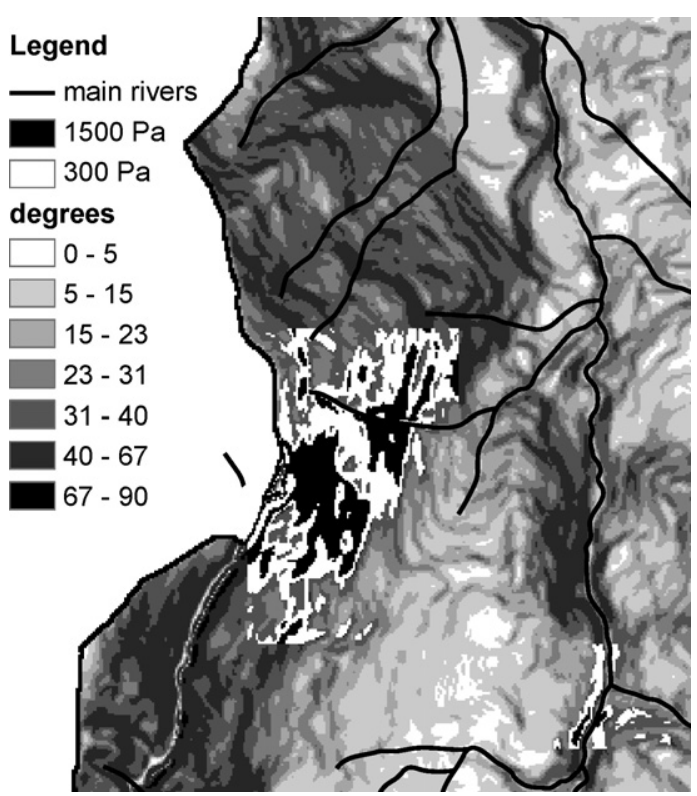

Fig. 5. Close-up view of the main landslide zone comparing simulations with root cohesions of $300 \mathrm{~Pa}$ (white) and $1500 \mathrm{~Pa}$ (black), superimposed on a map of slope angle.
Table 2

Number of landslides simulated for different values of root cohesion.

\begin{tabular}{ll}
\hline Root cohesion $(\mathrm{Pa})$ & Number of landslides \\
\hline 300 & 78 \\
700 & 56 \\
1000 & 42 \\
1500 & 25 \\
\hline
\end{tabular}

earlier, though, uncertainties in model parameterization mean that some of the model pixels are unconditionally unstable and therefore fail independently of the simulation conditions. A more realistic consideration of landslide occurrence requires that these be eliminated from the output, leaving only those landslides relevant to the simulation period. In this case this was achieved by eliminating all the landslides which occurred in the first $24 \mathrm{~h}$ of the simulation. The number of simulated landslides is then much smaller and more realistic. Repeating the simulation with different root cohesions gives the results shown in Table 2, where the conclusion is clear: the stronger the cohesion, the less is the number of landslides. Again this indicates the potential for controlling landslide occurrence through tree plantation.

In view of the imperfect data availability, it is acknowledged that the numbers of simulated landslides and their spatial distribution would vary with different realizations of the basin soil, topography and rainfall. However, the direction of change associated with greater root cohesion would not be expected to change.

\section{Conclusions}

The Guabalcón simulation demonstrates the use of physically based, spatially distributed landslide models for identifying the areas of a river basin which are most susceptible to shallow landsliding and for quantifying the effect of different vegetation covers on landslide incidence. Such models can therefore be proposed as a 
means of testing and selecting strategies for the targeted reforestation of basins, i.e. of managing those parts of a basin most critical for landslide occurrence. Of particular significance is that this task can be pursued even with imperfect data availability. In this case, the rainfall regime could not be characterized entirely satisfactorily and the soil parameters were evaluated from spatially limited samples. A great advantage of physically based models, though, is that, if there is a lack of measured data, their parameters can still be evaluated using data from the literature, regional transpositions and professional judgement, options not open to simpler types of model. Such parameterization is sufficient to allow an initial exploration of a problem area. This can involve running the model, carrying out a systematic investigation of trends and patterns (e.g. of vegetation control on landslide occurrence) and quantifying the uncertainty, and thus the potential costs, associated with making decisions on the basis of imperfect data provision. Of course, the poorer the availability of measured data for constraining model parameterization, the greater is the uncertainty in the model output. The extent to which that uncertainty is acceptable has to be weighed against the cost of its reduction through the collection of more detailed spatially and temporally varying data. However, an agency will be faced with making a decision on, for example, basin reforestation to control landsliding, whatever the availability of data. Physically based modelling can improve the efficiency of that decision-making by making the best use of those data which are available. The model output, though, should be interpreted carefully in the light of the parameter uncertainty.

\section{Future needs}

Improved model performance could be obtained from improved parameterization and from advances in model design. Examples of the former include:

- high-resolution topographic data. Even current DEMs with horizontal resolutions of 10 or $20 \mathrm{~m}$ may not be sufficient to represent the flow convergence zones which often form the sites of landslide occurrence. There is great interest, therefore, in the use of airborne LIDAR (LIght Detection And Ranging), which has the capability of providing vertical resolutions of a few centimetres and horizontal resolutions of a few decimetres to metres (e.g. McKean and Roering, 2004);

- spatially distributed soil property data. Soil property data are currently obtained from individual point measurements at soil pits or auger cores which, for practical reasons, cannot be carried out across the full basin scale. Future options for quantifying soil properties across the basin may include remote sensing techniques and the development of models which, for example, determine soil depth as a function of topography (e.g. Dietrich et al., 1995);

- calibration data. In order to test models, there is a particular need for basin-scale landslide inventories in which known (i.e. recorded or mapped) landslide events are linked to recorded rainfall events and for which river discharge and sediment transport records are also available. The rainfall data need to be at a sufficient resolution to represent local and elevation related dependencies.

There are many areas in which model design could be refined. These include:

- root cohesion. Current landslide models account for the binding effect of vegetation through a single general root cohesion value. However, there is considerable new understanding on how roots interact with the soil to provide additional apparent cohesion which could be incorporated. An exciting development would be the coupling of a root architecture and growth model (e.g. Dupuy et al., 2005; Danjon et al., 2008) with a hydrological-geotechnical landslide model, allowing feedback between forest growth (including root systems and water demand), soil moisture content and slope stability;

- slope stability. Current basin-scale models typically employ the one-dimensional infinite-slope stability model because of its practicality. However, this restricts accurate representation of slope conditions where groundwater flow or topography produce forces that are significant in directions other than slope-normal A more accurate approach would be to incorporate the twodimensional rotational slip model (Collison and Griffiths, 2004).

\section{Acknowledgements}

The Guabalcón simulation was carried out within the EPIC FORCE project (Evidence-based Policy for Integrated Control of Forested River Catchments in Extreme Rainfall and Snowmelt), which was funded by the European Commission within the 6th Framework Programme as part of its programme of Specific Measures in Support of International Cooperation under Contract Number INCO-CT2004-510739. Two anonymous reviewers are thanked for comments that allowed a significant strengthening of the paper.

\section{References}

Abernethy, B., Rutherfurd, I.D., 2001. The distribution and strength of riparian tree roots in relation to riverbank reinforcement. Hydrol. Process. 15, 63-79.

Adams, R., Parkin, G., Rutherford, J.C., Ibbitt, R.P., Elliott, A.H., 2005. Using a rain fall simulator and a physically based hydrological model to investigate runof processes in a hillslope. Hydrol. Process. 19, 2209-2223.

Adams, R., Elliott, S., 2006. Physically based modelling of sediment generation and transport under a large rainfall simulator. Hydrol. Process. 20, 2253-2270.

Amaranthus, M.P., Rice, R.M., Barr, N.R., Ziemer, R.R., 1985. Logging and forest roads related to increased debris slides in southwestern Oregon. J. Forest. 83, 229-233.

Bathurst, J.C., Wicks, J.M., O'Connell, P.E., 1995. The SHE/SHESED basin scale water flow and sediment transport modelling system. In: Singh, V.P. (Ed.), Computer Models of Watershed Hydrology. Water Resources Publications, Highlands Ranch, CO, USA, pp. 563-594.

Bathurst, J.C., Sheffield, J., Vicente, C., White, S.M., Romano, N., 2002. Modelling large basin hydrology and sediment yield with sparse data: the Agri basin, southern Italy. In: Geeson, N.A. Brandt, C.J., Thornes, J.B. (Eds.), Mediterranean Desertification: A Mosaic of Processes and Responses. Wiley, Chichester, UK, pp. 397-415

Bathurst, J.C., Ewen, J., Parkin, G., O'Connell, P.E., Cooper, J.D., 2004. Validation of catchment models for predicting land-use and climate change impacts. 3. Blind validation for internal and outlet responses. J. Hydrol. 287, 74-94.

Bathurst, J.C., Moretti, G., El-Hames, A., Moaven-Hashemi, A., Burton, A., 2005. Scenario modelling of basin-scale, shallow landslide sediment yield, Valsassina, Italian Southern Alps. Nat. Hazard. Earth Syst. Sci. 5, 189-202.

Bathurst, J.C., Burton, A., Clarke, B.G., Gallart, F., 2006. Application of the SHETRAN basin-scale, landslide sediment yield model to the Llobregat basin, Spanish Pyrenees. Hydrol. Process. 20, 3119-3138.

Bathurst, J.C., Moretti, G., El-Hames, A., Beguería, S., García-Ruiz, J.M., 2007. Modelling the impact of forest loss on shallow landslide sediment yield, Ijuez river catchment, Spanish Pyrenees. Hydrol. Earth Syst. Sci. 11, 569-583.

Beven, K.J., 2001. Rainfall-Runoff Modelling: The Primer. Wiley, Chichester, UK, 360 pp.

Beven, K., Binley, A., 1992. The future of distributed models: model calibration and uncertainty prediction. Hydrol. Process. 6, 279-298.

Borga, M., Dalla Fontana, G., Gregoretti, C., Marchi, L., 2002. Assessment of shallow landsliding by using a physically based model of hillslope stability. Hydrol. Process. 16, 2833-2851.

Burton, A., Bathurst, J.C., 1998. Physically based modelling of shallow landslide sediment yield at a catchment scale. Environ. Geol. 35, 89-99.

Burton, A., Arkell, T.J., Bathurst, J.C., 1998. Field variability of landslide model parameters. Environ. Geol. 35, 100-114.

Buytaert, W., Wyseure, G., De Bièvre, B., Deckers, J., 2005. The effect of land-use changes on the hydrological behaviour of Histic Andosols in south Ecuador Hydrol. Process. 19, 3985-3997.

Caine, N., 1980. The rainfall intensity-duration control of shallow landslides and debris flows. Geogr. Ann. 62A, 23-27.

Chen, H., Lee, C.F., 2003. A dynamic model for rainfall-induced landslides on natural slopes. Geomorphology 51, 269-288. 
Claessens, L., Schoorl, J.M., Veldkamp, A., 2007. Modelling the location of shallow landslides and their effects on landscape dynamics in large watersheds: an application for Northern New Zealand. Geomorphology 87, 16-27.

Clarke, R.T., 1973. Mathematical models in hydrology. In: Irrigation and Drainage Paper 19. Food and Agriculture Organization of the United Nations, Rome.

Collison, A., Griffiths, J., 2004. Modelling slope instability. In: Wainwright, J., Mulligan, M. (Eds.), Environmental Modelling: Finding Simplicity in Complexity. Wiley, Chichester, UK, pp. 197-209.

Crosta, G.B., Frattini, P., 2008. Preface: rainfall-induced landslides and debris flows. Hydrol. Process. 22, 472-477.

Danjon, F., Barker, D.H., Drexhage, M., Stokes, A., 2008. Using three-dimensional plant root architecture in models of shallow-slope stability. Ann. Bot. 101, 1281-1293.

Dhakal, A.S., Sidle, R.C., 2003. Long-term modelling of landslides for different forest management practices. Earth Surf. Process. Landf. 28, 853-868.

Dhital, M.R., 2003. Causes and consequences of the 1993 debris flows and landslides in the Kulekhani watershed, central Nepal. In: Rickenmann, D., Chen, C.-I. (Eds.), Proceedings of the third International Conference on Debris-Flow Hazards Mitigation: Mechanics, Prediction and Assessment, vol. 2. Millpress, Rotterdam, Netherlands, pp. 931-942.

Dietrich, W.E., Reiss, R., Hsu, M.-L., Montgomery, D.R., 1995. A process-based model for colluvial soil depth and shallow landsliding using digital elevation data. Hydrol. Process. 9, 383-400.

Dietrich, W.E., Bellugi, D., Real de Asua, R., 2001. Validation of the shallow landslide model, SHALSTAB, for forest management. In: Wigmosta, M.S., Burgess, S.J. (Eds.), Land Use and Watersheds: Human Influence on Hydrology and Geomorphology in Urban and Forest Areas, Water Science and Application, vol. 2. American Geophysical Union, Washington, DC, pp. 195-227.

Douguédroit, A., 1981. Reafforestation in the French Southern Alps. Mt. Res. Dev. 1, 245-252.

Dupuy, L., Fourcaud, T., Stokes, A., Danjon, F., 2005. A density based approach for the modelling of root architecture: application to Maritime pine (Pinus pinaster Ait.) root systems. J. Theor. Biol. 236, 323-334.

Ebel, B.A., Loague, K., 2006. Physics-based hydrologic-response simulation: seeing through the fog of equifinality. Hydrol. Process. 20, 2887-2900.

Ewen, J., Parkin, G., 1996. Validation of catchment models for predicting land-use and climate change impacts. 1. Method. J. Hydrol. 175, 583-594.

Ewen, J., Parkin, G., O'Connell, P.E., 2000. SHETRAN: distributed river basin flow and transport modeling system. Proc. Am. Soc. Civ. Eng., J. Hydrol. Eng. 5, 250-258.

Gorsevski, P.V., Gessler, P.E., Boll, J., Elliot, W.J., Foltz, R.B., 2006. Spatially and temporally distributed modelling of landslide susceptibility. Geomorphology 80 , $178-198$.

Greenway, D.R., 1987. Vegetation and slope stability. In: Anderson, M.G., Richards K.S. (Eds.), Slope Stability. Wiley, Chichester, UK, pp. 187-230.

Guimarães, R.F., Montgomery, D.R., Greenberg, H.M., Fernandes, N.F., Gomes, R.A.T., de Carvalho Júnior, O.A., 2003. Parameterization of soil properties for a model of topographic controls on shallow landsliding: application to Rio de Janeiro. Eng. Geol. 69, 99-108.

Guthrie, R.H., 2002. The effects of logging on frequency and distribution of landslides in three watersheds on Vancouver Island, British Columbia. Geomorphology 4 273-292.

Guzzetti, F., Carrara, A., Cardinali, M., Reichenbach, P., 1999. Landslide hazard evaluation: a review of current techniques and their application in a multi-scale study, central Italy. Geomorphology 31, 181-216.

Guzzetti, F., Reichenbach, P., Ardizzone, F., Cardinali, M., Galli, M., 2006. Estimating the quality of landslide susceptibility models. Geomorphology 81, 166-184.

Harden, C.P., 2006. Human impacts on headwater fluvial systems in the northern and central Andes. Geomorphology 79, 249-263.

Hicks, D.M., Gomez, B., Trustrum, N.A., 2000. Erosion thresholds and suspended sediment yields, Waipaoa River Basin, New Zealand. Water Resour. Res. 36, $1129-1142$.

Iida, T., 2004. Theoretical research on the relationship between return period of rainfall and shallow landslides. Hydrol. Process. 18, 739-756.

Iverson, R.M., Reid, M.E., 1992. Gravity-driven groundwater flow and slope failure potential. 1. Elastic effective-stress model. Water Resour. Res. 28, 925-938.
Keim, R.F., Skaugset, A.E., 2003. Modelling effects of forest canopies on slope stability. Hydrol. Process. 17, 1457-1467.

Kessel, M.L., 1985. Timber harvest, landslides, streams, and fish habitat on the Oregon Coast. J. Forest. 83, 606-607.

Larson, C.L., Albertin, W., 1984. Controlling erosion and sedimentation in the Panama Canal watershed. Water Int., 161-164.

López, J.L., Perez, D., García, R., 2003. Hydrologic and geomorphic evaluation of the 1999 debris-flow event in Venezuela. In: Rickenmann, D., Chen, C.-L. (Eds.) Proceedings of the third International Conference on Debris-Flow Hazards Mitigation: Mechanics, Prediction and Assessment, vol. 2. Rotterdam, Netherlands. Millpress, pp. 989-1000.

Lu, S.-Y., Cheng, J.D., Brooks, K.N., 2001. Managing forests for watershed protection in Taiwan. Forest Ecol. Manage. 143, 77-85

Lukey, B.T., Sheffield, J., Bathurst, J.C., Hiley, R.A., Mathys, N., 2000. Test of the SHETRAN technology for modelling the impact of reforestation on badlands runoff and sediment yield at Draix, France. J. Hydrol. 235, 44-62.

McKean, J., Roering, J., 2004. Objective landslide detection and surface morphology mapping using high-resolution airborne laser altimetry. Geomorphology 57, 331-351.

Meisina, C., Scarabelli, S., 2007. A comparative analysis of terrain stability models for predicting shallow landslides in colluvial soils. Geomorphology 87, 207223.

Montgomery, D.R., Dietrich, W.E., 1994. A physically based model for the topographic control on shallow landsliding. Water Resour. Res. 30, 1153-1171.

Montgomery, D.R., Dietrich, W.E., Torres, R., Anderson, S.P., Heffner, J.T., Lague, K. 1997. Hydrologic response of a steep unchanneled valley to natural and applied rainfall. Water Resour. Res. 33, 91-109.

Pearce, A.J., O'Loughlin, C.L., Jackson, R.J., Zhang, X.B., 1987. Reforestation: on-site effects on hydrology and erosion, eastern Raukumara range, New Zealand. In: Forest Hydrology and Watershed Management, International Association of Hydrological Sciences Publication No. 167, pp. 489-497.

Preston, N.J., Crozier, M.J., 1999. Resistance to shallow landslide failure through rootderived cohesion in east coast hill country soils, North Island, New Zealand. Earth Surf. Process. Landf. 24, 665-675.

Reid, L.M., Page, M.J., 2002. Magnitude and frequency of landsliding in a large New Zealand catchment. Geomorphology 49, 71-88.

Rice, R.M., Corbett, E.S., Bailey, R.G., 1969. Soil slips related to vegetation, topography, and soil in southern California. Water Resour. Res. 5, 647-659.

Sidle, R.C., Pearce, A.J., O'Loughlin, C.L., 1985. Hillslope Stability and Land Use. Water Resources Monograph 11. American Geophysical Union, Washington, DC, 140 pp.

Sidle, R.C., Ochiai, H., 2006. Landslides: Processes, Prediction, and Land Use. Water Resources Monograph 18. American Geophysical Union, Washington, DC, 312 pp.

Tejwani, K.G., 1984. Reservoir sedimentation in India-its causes, control and future course of action. Water Int. 9, 150-154.

Vanacker, V., Vanderschaeghe, M., Govers, G., Willems, E., Poesen, J., Deckers, J., De Bièvre, B., 2003. Linking hydrological, infinite slope stability and land-use change models through GIS for assessing the impact of deforestation on slope stability in high Andean watersheds. Geomorphology 52, 299-315.

Vanacker, V., von Blanckenburg, F., Govers, G., Molina, A., Poesen, J., Deckers, J., Kubik, P., 2007. Restoring dense vegetation can slow mountain erosion to near natural benchmark levels. Geology 35, 303-306.

Van Genuchten, M.Th., 1980. A closed form equation for predicting the hydraulic conductivity of unsaturated soils. Soil Sci. Soc. Am. J. 44, 892-898.

Wicks, J.M., Bathurst, J.C., 1996. SHESED: a physically based, distributed erosion and sediment yield component for the SHE hydrological modelling system. J. Hydrol. $175,213-238$.

Wu, W., Sidle, R.C., 1995. A distributed slope stability model for steep forested basins. Water Resour. Res. 31, 2097-2110.

Wu, W., Sidle, R.C., 1997. Application of a distributed Shallow Landslide Analysis Model (dSLAM) to managed forested catchments in Oregon, USA. In: Human Impact on Erosion and Sedimentation, International Association of Hydrological Sciences Publication No. 245, pp. 213-221. 